\title{
The prediction of neutrophil to Iymphocyte ratio for outcomes in ischemic stroke
}

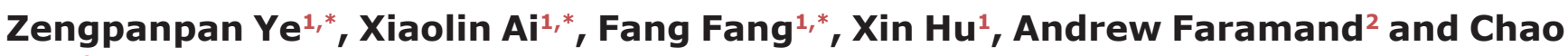 \\ You $^{1}$ \\ ${ }^{1}$ Department of Neurosurgery, West China Hospital of Sichuan University, Chengdu 610041, Sichuan, China \\ ${ }^{2}$ Department of Neurosurgery, University of Pittsburgh Medical Center, Pittsburgh, Pennsylvania, United States of America \\ *These authors have contributed equally to this work \\ Correspondence to: Chao You, email:youc0118@163.com \\ Keywords: neutrophil to lymphocyte ratio; ischemic stroke; meta-analysis \\ Received: August 29, $2017 \quad$ Accepted: November 13, $2017 \quad$ Published: December 01, 2017 \\ Copyright: Ye et al. This is an open-access article distributed under the terms of the Creative Commons Attribution License 3.0 \\ (CC BY 3.0), which permits unrestricted use, distribution, and reproduction in any medium, provided the original author and source \\ are credited.
}

\section{ABSTRACT}

Objective: Neutrophil to lymphocyte ratio (NLR) is a prognostic inflammatory biomarker in patients with cardiovascular disease and hemorrhagic stroke. This metaanalysis aims to evaluate the prognostic values of NLR in predicting clinical outcomes in patients with ischemic stroke.

Methods: A literature search was performed using the databases PubMed, EMBASE, Cochrane Central Register of Controlled Trials and China National Knowledge Infrastructure. Two reviewers independently retrieved papers that met the inclusion criteria. Subgroup analyses were performed using in-hospital mortality, 90-day mortality and 90 -day poor outcomes $(\mathrm{mRS}>2)$ as the outcome measures.

Results: Eight studies with $\mathbf{3 8 5 5}$ patients were included in the analysis. An elevated NLR was a strong predictor for in-hospital mortality (OR: 1.05; 95\% CI: 1.03-1.07, $\mathrm{p}<0.001$ ) and for 90-day poor outcomes (OR: 2.28 ; $95 \%$ CI: 1.39-3.73, p<0.001), but not for 90-day mortality (OR: $3.04 ; 95 \%$ CI: $0.74-12.55, p=0.12$ ). After performing subgroup analysis, the NLR was found to predict 90-day mortality with a high $(>5)$ cut-off values (OR: 6.69; 95\% CI: 1.70-26.33, p=0.007). The lower cut-off values had no significance (OR: $2.17 ; 95 \% \mathrm{CI}: 0.43-10.86, \mathrm{p}=0.35$ ).

Conclusions: A high NLR was significantly associated with higher rates of inhospital mortality and 90-day poor outcome in patients with ischemic stroke, especially with a high mean NLR or high cut-off values. With a high cut-off value $(>5)$, NLR could predict the 90-day mortality after ischemic stroke.

\section{INTRODUCTION}

Ischemic stroke is the major cause of stroke and accounts for $80-85 \%$ of all cases [1-3]. Ischemic stroke is associated with high rates of mortality and morbidity [4]. The subsequent inflammatory reaction involves cytokine release and recruitment of inflammatory cells. This inflammatory reaction is responsible for the secondary brain injury, and is a major prognostic factor after ischemic stroke $[5,6]$.
Many inflammatory biomarkers have been identified as possible prognostic predictors in ischemic stroke. A review [7] of five studies demonstrated that the $\mathrm{C}$ reactive protein is significantly associated with poor longterm clinical outcomes in patients with ischemic stroke. Elevated white blood cell (WBC) counts after stroke onset could also predict the severity of stroke, the incidence of disability, and short-term mortality [8]. High neutrophil counts were correlated with the larger infarct volumes [9]. NLR is the ratio of neutrophil and lymphocyte and 
reflects the balance of the immune response. An imbalance of the immune system involving the NLR can be used as a biomarker for a systematic inflammatory response. In addition, it is used to predict the prognosis of patients with various cancers $[10,11]$, cardiovascular diseases $[12,13]$ and hemorrhagic stroke [14-16]. Recently, NLR was used to predict in-hospital mortality [17, 18], 90-day mortality [19-21] and 90-day poor outcomes $(\mathrm{mRS} \geq 3)$ [4, 21-23] in patients with ischemic stroke.

No systemic analysis looking at the predictive ability of NLR in patients with ischemic stroke. Thus, we performed a meta-analysis to determine the use of NLR in predicting clinical outcomes in patients with ischemic stroke.

\section{MATERIALS AND METHODS}

\section{Search strategy}

Following the PRISMA flow diagram [24] (Figure 1), A literature search was conducted using the databases PubMed, EMBASE, Cochrane Central Register of Controlled Trials and China National Knowledge Infrastructure (CNKI) using the key words 'ischemic stroke' OR ‘brain infarction' AND 'lymphocyte' AND 'neutrophil'. The search looked at articles published from the time of creation of the database up until August $1^{\text {st }}$ 2017. Additional studies were collected by reviewing the references listed in related articles.

\section{Study selection}

The full-text of the selected studies were independently evaluated by two reviewers. Inclusion criteria consisted of: 1 - patients diagnosed with ischemic stroke on NCCT or MRI; 2- articles reporting the OR and $95 \%$ CI of NLR on mortality or poor outcomes, or the available data allows for the calculation of the OR and 95\% CI; 3- Case-control studies, cohort studies or randomized controlled studies (RCTs). Review articles, case reports, and reports using animal models, were excluded.

\section{Data extraction}

The data were extracted according to a standard data form. Extracted data included author titles, publication year, country, study design, number of patients, mean age, gender, mean NLR, National Institutes of Health Stroke Scale (NIHSS) or Glasgow coma scale (GCS), study period, NOS score, hematoma/ischemic volume, time of performance of laboratory test, cut-off value of NLR, odds ratio (OR) and 95\%CI of NLR on mortality and poor outcomes. If the ORs of multivariate regression analysis were unavailable, the ORs of univariate regression were used. The end points included in-hospital mortality, 90-days mortality, and the 90-day poor outcomes (mRS from 3 to 6).

\section{Quality assessment of the selected articles}

The quality of cohort and case-control studies was evaluated by two reviewers independently utilizing the Newcastle-Ottawa scale criteria [25]. A Newcastle-Ottawa scale (NOS) score $\geq 7$ was set to define a report as a high quality report.

\section{Data analysis}

The OR and 95\%CI of NLR on mortality and poor outcomes were pooled by Review Manager Version 5.3 (Cochrane collaboration, Oxford, UK) and the publication bias were assessed by STATA 13.0 (STATA Corporation, College Station, TX). When there was a significant heterogeneity with $\mathrm{I}^{2}>50 \%$ or $\mathrm{p}<0.10$, the random-effects model was used, otherwise, the fixed-effects model was adopted. The sensitivity analysis were used if the heterogeneity was quite high. The subgroup analyses were performed by countries, study design, mean NLR, cut-off values, time from onset to laboratory test, and the logistic regression models. The publication bias was assessed by Funnel plot with Begg rank correlation. If $p$ value $<0.05$ was set for significant statistical difference.

\section{RESULTS}

\section{Literature research}

The titles and abstracts of 168 articles were reviewed and 135 unrelated articles were excluded. After full review of the remaining 33 articles, 8 studies met the inclusion criteria and where used in the constriction of this meta-analysis. 25 articles were excluded, of which 19 articles failed to meet the inclusion criteria, and 6 articles did not report the required data.

\section{Study characteristics}

A total of 8 studies [4, 17-23] of 3855 patients were included and the study characteristics of were listed in Table 1 . All studies (2 prospective and 6 retrospective) were published between 2013 and 2017 with mean age from 62 to 70 years. The mean NLR ranged from 2.1 to 4.0 with the cut-off values between 2.39 and 5.9. All of the ORs and 95\% CI were calculated using multiple regression analysis other than two studies $[19,20]$. All the included studies had a high quality with NOS score $\geq 7$.

\section{In-hospital mortality}

Two articles of 2093 patients were pooled for the association of NLR and the in-hospital mortality. The results showed that a high NLR increased the risk of 
in-hospital mortality with OR of $1.05(95 \% \mathrm{CI}, 1.03$ $1.07, \mathrm{p}<0.001$, Figure 2) and no significant heterogeneity $\left(\mathrm{I}^{2}=43 \%\right.$ and $\left.\mathrm{p}=0.19\right)$.

\section{0-day mortality}

After pooling the results of three articles with 1032 patients, we found that a high NLR was not associated with the 90-day mortality with an OR of $3.04(95 \% \mathrm{CI}$, $0.74-12.55, \mathrm{p}=0.12$, Figure 3 ). Using sensitivity analysis, we identified significant heterogeneity originating from the study of Maestrini [20]. After exclusion of the aforementioned study, there was no heterogeneity $\left(\mathrm{I}^{2}=0 \%\right.$ and $\mathrm{p}=0.87$ ) between the remaining studies with $\mathrm{OR}$ of 6.18 (95\%CI, 2.38-16.07, $\mathrm{p}<0.001)$.

\section{Subgroup analysis}

Subgroup analyses was performed according to study design, cut-off values of NLR, and the types of logistic regression (Table 2). The pooled ORs were $1.08(95 \% \mathrm{CI}$, $1.03-1.13, \mathrm{p}=0.001)$ in a retrospective article and 6.18 $(95 \% \mathrm{CI}, 2.38-16.07, \mathrm{p}<0.001)$ in two perspective studies.

One article reported high cut-off values of NLR $(>5)$, the OR was $6.69(95 \% \mathrm{CI}, 1.70-26.33, \mathrm{p}=0.007)$.

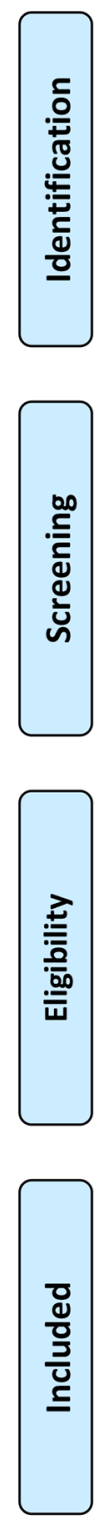

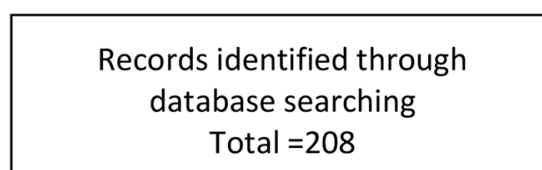

Total $=208$

\section{Additional records identified through the reference}

$(n=2)$

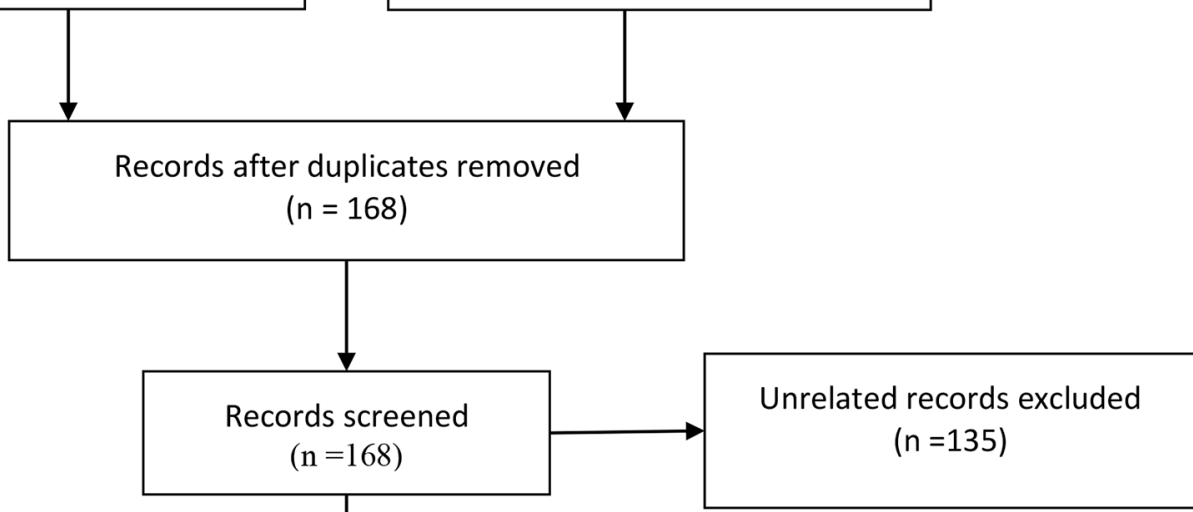

Full-text articles assessed for eligibility $(n=33)$

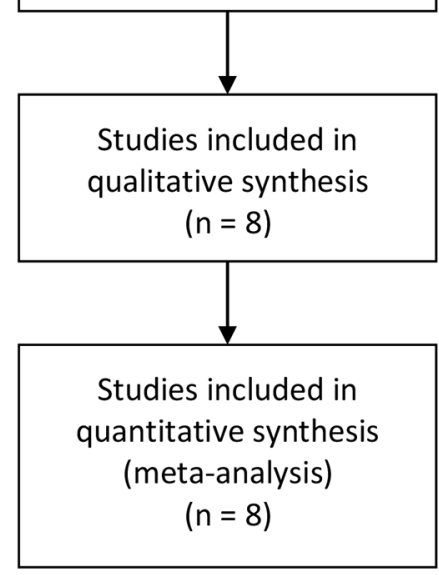

Full-text articles excluded ( $n=25)$

Not meet criteria $=19$ Inappropriate data $=6$

Figure 1: The flow diagram of procedure to search the included studies. 
Table 1: Characteristics of included studies

A

\begin{tabular}{|c|c|c|c|c|c|c|c|c|c|c|c|}
\hline Author & Year & Country & $\begin{array}{l}\text { Study } \\
\text { design }\end{array}$ & $\begin{array}{c}\text { Patients } \\
\text { (n) }\end{array}$ & $\begin{array}{c}\text { Sex } \\
(\mathrm{M} / \mathrm{F})\end{array}$ & $\begin{array}{l}\text { Mean age } \\
\text { (years) }\end{array}$ & $\begin{array}{l}\text { Mean } \\
\text { NLR }\end{array}$ & NIHSS & Treatments & $\begin{array}{l}\text { Study } \\
\text { period }\end{array}$ & $\begin{array}{l}\text { NOS } \\
\text { score }\end{array}$ \\
\hline Xue, J. 2017 & 2017 & China & retrospective & 280 & $173 / 107$ & 62 & 2.1 & - & $\begin{array}{c}\text { Multiplicate } \\
\text { (endovascular) }\end{array}$ & 2014-2015 & 8 \\
\hline Qun, S. & 2016 & China & retrospective & 143 & $80 / 63$ & 70 & 2.75 & 6 & - & $2015-2016$ & 7 \\
\hline Celikbilek, A. & 2014 & Turkey & prospective & 70 & $33 / 37$ & 69 & 3.3 & - & - & 2010-2011 & 7 \\
\hline Fang, Y. N. & 2017 & Taiwan & retrospective & 1731 & $1092 / 639$ & 68 & 3.99 & - & $\begin{array}{l}\text { Antiplatelet } \\
\text { Drugs }\end{array}$ & $2010-2017$ & 8 \\
\hline Maestrini, I. & 2015 & Finland & prospective & 846 & $430 / 416$ & 71 & 3.40 & 10 & rtPA & $2010-2015$ & 9 \\
\hline Fan, L. & 2017 & China & retrospective & 362 & $216 / 146$ & 63 & 4.0 & 9 & - & 2014-2015 & 7 \\
\hline Brooks, S. D. & 2013 & USA & retrospective & 116 & $53 / 63$ & 67 & 3.74 & 17 & Endovascular & 2008-2011 & 7 \\
\hline Zhai, M.M. & 2017 & China & retrospective & 307 & $227 / 80$ & 63 & 2.90 & 4 & - & 2014-2015 & 7 \\
\hline
\end{tabular}

NIHSS: National Institutes of Health Stroke Scale, GCS: Glass coma scale, NOS: Newcastle-Ottawa scale score.

B

\begin{tabular}{|c|c|c|c|c|c|c|}
\hline Author & $\begin{array}{l}\text { Hematoma/ } \\
\text { ischemic } \\
\text { volume }(\mathrm{ml})\end{array}$ & $\begin{array}{c}\text { Time from onset } \\
\text { to laboratory test } \\
\text { (hours) }\end{array}$ & $\begin{array}{c}\text { Cut-off } \\
\text { value }\end{array}$ & poor outcome $(\mathrm{OR})^{\#}$ & mortality $(\mathrm{OR})^{\#}$ & Follow up \\
\hline Xue, J. 2017 & 1.9 & 24 & 2.39 & $1.455(1.083-1.956)$ & - & 90-day \\
\hline Qun, S. & 1.57 & 12 & 2.99 & $2.547(1.567-4.137)$ & - & 90-day \\
\hline Celikbilek, A. & - & $<24$ & 4.1 & - & $5.73(1.51-21.82)^{*}$ & 90-day \\
\hline Fang, Y. N. & - & 48 & 3.2 & - & $1.04(1.01-1.06)$ & In-hospital \\
\hline Maestrini, I. & - & 2.4 & 4.8 & $3.97(2.94-5.35)^{*}$ & $1.08(1.03-1.13)$ & 90-day \\
\hline Fan, L. & - & $<48$ & Per 1 & - & $1.07(1.03-1.11)$ & In-hospital \\
\hline Brooks, S. D. & - & - & 5.9 & $6.73(1.27-35.73)$ & $6.69(1.7-26.3)$ & 90-day \\
\hline Zhai, M.M. & & $4 \mathrm{~h}$ & 2.84 & $1.427(1.247-1.634)$ & - & 90-day \\
\hline
\end{tabular}

\#: multivariate regression analysis, ${ }^{\text {: }}$ : univariate regression analysis, OR: odds ratio.

The low cut-off values of NLR $(<5)$, the OR for 90day mortality was $2.17(95 \% \mathrm{CI}, 0.43-10.86, \mathrm{p}=0.35)$. The pooled ORs of the study were $5.73(95 \% \mathrm{CI}, 1.51$ $21.74, \mathrm{p}=0.01)$ and $2.35(95 \% \mathrm{CI}, 0.40-13.77, \mathrm{p}=0.34)$ by univariate regression analysis and multivariate regression analysis, respectively.

\section{0-day poor outcomes}

Five articles reporting data from 1692 subjects were pooled to evaluate the relationship between NLR and 90-day poor outcomes. The results of the five articles suggest that a higher NLR is associated with higher poor outcome rates in patients with ischemic stroke with OR of 2.28 (95\%CI, 1.39-3.73, p $<0.001$, Figure 4). Significant heterogeneity was detected $\left(\mathrm{I}^{2}=91 \%, \mathrm{p}<0.001\right)$ between these studies. Using sensitivity analysis we attributed the origin of heterogeneity to the study of Maestrini [20]. After excluding this study, the heterogeneity decreased with $\mathrm{I}^{2}=64 \%$ and OR of $1.71(95 \% \mathrm{CI}, 1.26-2.31$, $\mathrm{p}<0.001)$.

\section{Subgroup analysis}

In the China and non-China groups, the pooled ORs were 1.60 (95\%CI, 1.24-2.08, p<0.001) and 4.04 $(95 \% \mathrm{CI}, 3.00-5.42, \mathrm{p}<0.001)$ respectively. The pooled ORs of four retrospective studies was 1.71 (95\%CI, $1.26-2.31, \mathrm{p}<0.001)$ and one prospective study reported the OR of $3.97(95 \% \mathrm{CI}, 2.94-5.36, \mathrm{p}<0.001)$ for 90 -day poor outcome. In low and high mean NLR group, the pooled OR were 4.04(95\%CI, 3.00-5.42, $\mathrm{p}<0.001)$ and $1.60(95 \% \mathrm{CI}, 1.24-2.08, \mathrm{p}<0.001)$ respectively. The pooled ORs were $6.73(95 \% \mathrm{CI}, 1.27-35.66, \mathrm{p}=0.03)$ in high cutoff group $(>5)$ and $2.11(95 \% \mathrm{CI}, 1.28-3.49, \mathrm{p}=0.004)$ in low cut-off group $(<5)$. Four studies reported the time from 
onset to laboratory test and the time ranged from 2.4 to 48 hours. The pooled ORs of study were 3.97 (95\%CI, 2.94$5.36, \mathrm{p}<0.001)$ and $1.71(95 \% \mathrm{CI}, 1.26-2.31, \mathrm{p}=0.0006)$ by univariate regression analysis and multivariate regression analysis respectively.

\section{publication bias}

The funnel plots showed no publication bias for 90-day mortality and 90-day poor outcomes (Figure 5). Begg's test performed using STATA 13.0 also showed no evidence of publication bias $(\mathrm{p}=0.296$ and $\mathrm{p}=0.462)$.

\section{DISCUSSION}

Inflammation plays an important role in the development of ischemic stroke [3]. NLR reflects the immune status (lymphocytes) [26] and the degree of inflammatory infiltration (neutrophil) [26-28]. Recently,
NLR was considered as a predictor for clinical outcomes in hemorrhagic $[14,15,29]$ and ischemic stroke $[17,20$, $30]$. To our best knowledge, the present study is the first meta-analysis to evaluate the predictive value of NLR for the clinical outcomes in patients with ischemic stroke. We found that a high NLR was associated with higher rates of in-hospital mortality and 90-day poor outcomes, but not for the 90-day mortality in patients with ischemic stroke.

The inflammatory response increases the risk of hemorrhagic transformation [31], damage to the BBB and development of cerebral edema [32]. NLR reflects the ensuing inflammatory reaction after ischemic stroke, which could explain the fact that NLR could predict the clinical outcome.

The higher NLR was associated with 90-day mortality in prospective groups and retrospective groups, which was not consistent with the pooled results of all included studies. In addition, we found the OR of prospective studies (6.18) was higher than the OR of

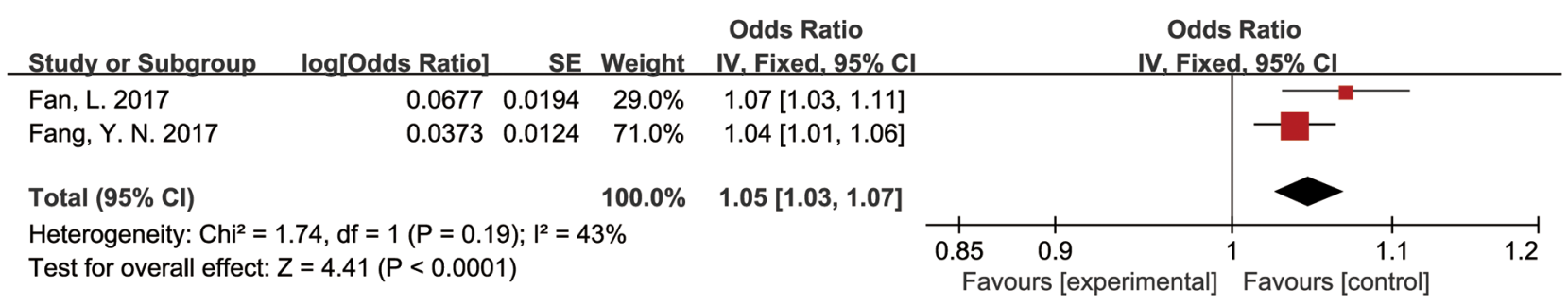

Figure 2: Forest plots for association of NLR and in-hospital mortality.

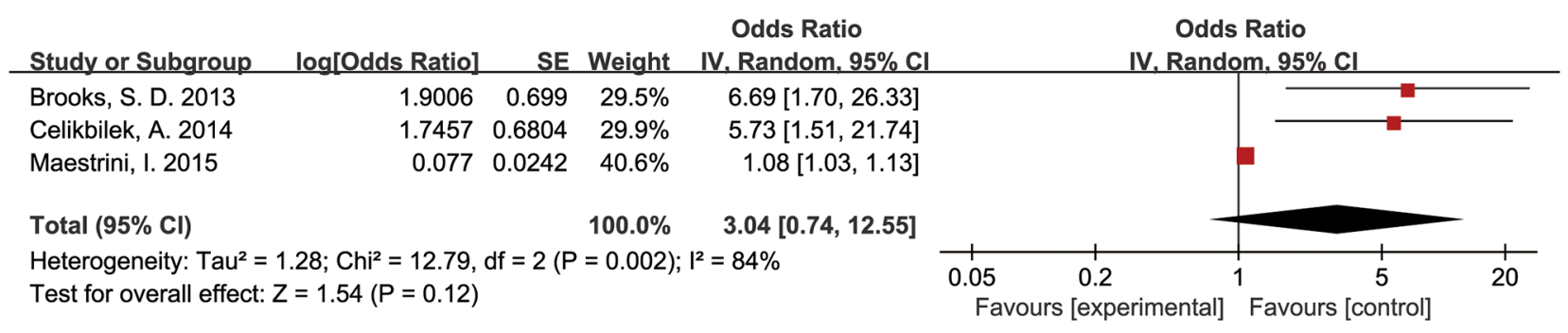

Figure 3: Forest plots for association of NLR and 90-day mortality.

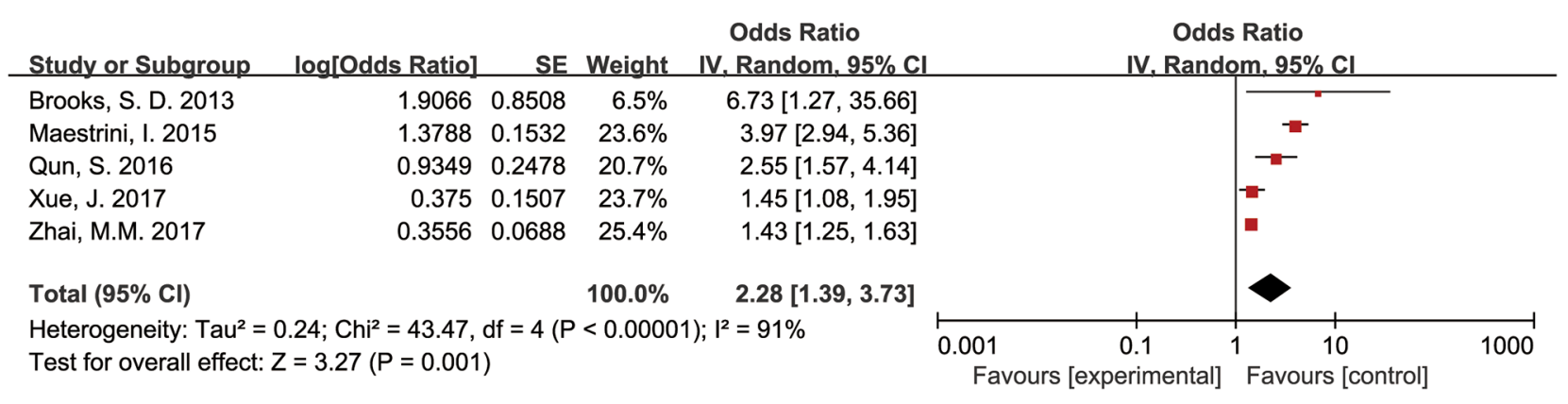

Figure 4: Forest plots for association of NLR and 90-day poor outcomes. 
Table 2: Subgroup analyses results of 90-day mortality

\begin{tabular}{llcccc}
\hline Groups & N & Model & Pooled OR (95\% CI) & p value & Heterogeneity (I' $\mathbf{I}^{2}$ P) \\
\hline Total & 3 & random & $3.04(0.74-12.55)$ & 0.12 & $0.002,84 \%$ \\
Retrospective & 1 & - & $1.08(1.03-1.13)$ & 0.001 & - \\
Prospective & 2 & fixed & $6.18(2.38-16.07)$ & $<0.001$ & $0.87,0 \%$ \\
Cut-off $>5$ & 1 & - & $6.69(1.70-26.33)$ & 0.007 & - \\
Cut-off $<5$ & 2 & random & $2.17(0.43-10.86)$ & 0.35 & $0.01,83 \%$ \\
Univariate regression analysis & 1 & - & $5.73(1.51-21.74)$ & 0.01 & - \\
Multivariate regression analysis & 2 & random & $2.35(0.40-13.77)$ & 0.34 & $0.009,85 \%$ \\
\hline
\end{tabular}

$\mathrm{N}$ : number of included studies, OR: odds ratio, CI: confidence interval.

retrospective studies (1.08). This might attribute to the selection bias of incurred in retrospective studies. There was a statistically significant association between high NLR and 90-day mortality in the high cut-off group $(>5)$, rather than in the low cut-off group $(<5)$, suggesting that higher cut-off values could improve the accuracy of predicting 90-day mortality and that the cut-off values should be more than 5 in patients with ischemic stroke. The association of NLR and 90-day mortality in patients with ischemic stroke might be influenced by confounding factors. Previous studies $[18,33]$ reported some independent predictors for mortality, such as age, NIHSS and the volume of infarct. With multivariate regression analysis, Maestrini [20] and Brooks [21] adjusted the outcomes with onset-to-treatment, gender, atrial fibrillation, systolic BP, recanalization, application of tissue plasminogen activator (tPA), and they found that NLR was independently associated with 90-day mortality. The study [19] that used univariate regression analysis also suggested that NLR at admission is a

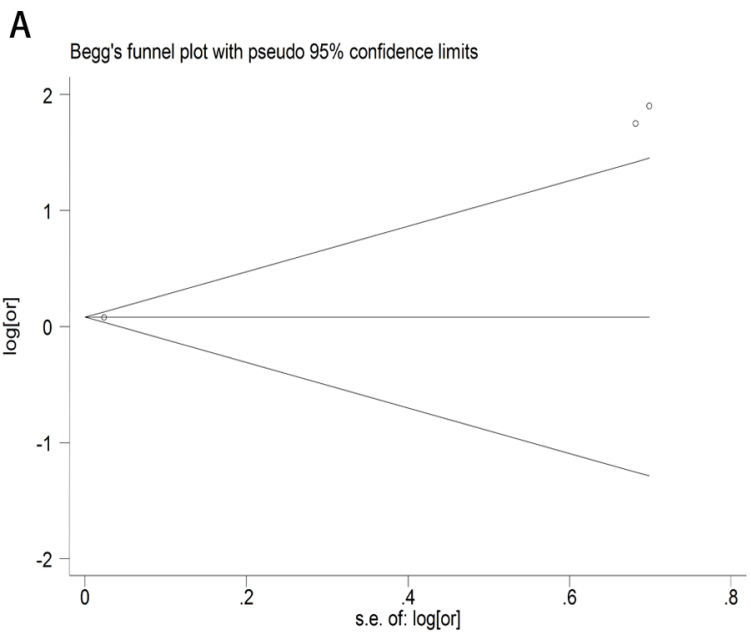

prognostic biomarker in acute ischemic stroke. However, after performing multivariate regression analysis, we found that the NLR was not an independent predictor for 90-day mortality with considering other factors. Compared with the 90-day poor outcomes, NLR was not an independent predictor for 90-day mortality and the risk of 90-day mortality was also influenced by other factors, such as age, history of myocardial infarction and National Institute of Health stroke scale (NIHSS) [20, 21]. One study [21] found the history of myocardial infarction and NIHSS had a higher OR (2.26 and 1.18) for 90-day mortality, and the NLR had a weaker predictive ability with OR of 1.08 . However, compared with other independent factors, the NLR had the similar or higher OR for 90-day poor outcomes [21]. After pooling the data of included studies, the number of patients increased and the effects of other factors would be greater than NLR, which might explain the difference of NLR prediction between the 90-day mortality and 90day poor outcomes.

B

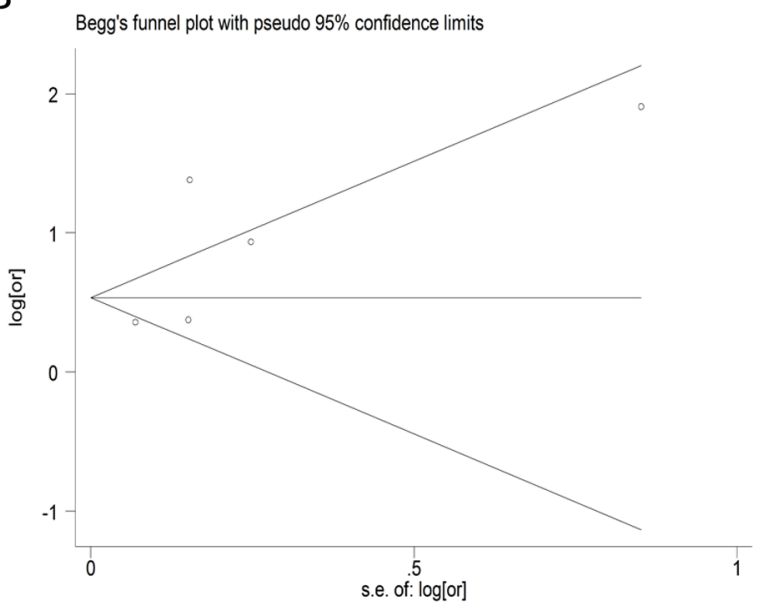

Figure 5: The Begg publication bias plot of the studies that reported 90-day mortality or 90-day poor outcomes, and no publication bias was found in these studies with $\mathrm{P}=0.296$ and 0.462 for 90 -day mortality (A) and 90 -day poor outcomes (B) respectively. 
Table 3: Subgroup analyses results of 90-day poor outcomes

\begin{tabular}{lccccc}
\hline Groups & $\mathbf{N}$ & Model & Pooled OR (95\% CI) & p value & Heterogeneity $\left(\mathbf{I}^{2}, \mathbf{P}\right)$ \\
\hline Total & 5 & random & $2.28(1.39-3.73)$ & 0.001 & $<0.001,91 \%$ \\
China & 3 & random & $1.60(1.24-2.08)$ & $<0.001$ & $0.08,61 \%$ \\
Non-China & 2 & fixed & $4.04(3.00-5.42)$ & $<0.001$ & $0.54,0 \%$ \\
Retrospective & 4 & random & $1.71(1.26-2.31)$ & 0.0006 & $0.04,64 \%$ \\
Prospective & 1 & - & $3.97(2.94-5.36)$ & $<0.001$ & - \\
Mean NLR $>3$ & 2 & fixed & $4.04(3.00-5.42)$ & $<0.001$ & $0.54,0 \%$ \\
$<3$ & 3 & random & $1.60(1.24-2.08)$ & $<0.001$ & $0.08,61 \%$ \\
Cut-off $>5$ & 1 & - & $6.73(1.27-35.66)$ & 0.03 & - \\
$<5$ & 4 & random & $2.11(1.28-3.49)$ & 0.004 & $<0.001,93 \%$ \\
Univariate regression analysis & 1 & - & $3.97(2.94-5.36)$ & $<0.001$ & - \\
Multivariate regression analysis & 4 & random & $1.71(1.26-2.31)$ & 0.0006 & $0.04,64 \%$
\end{tabular}

$\mathrm{N}$ : number of included studies, OR: odds ratio, CI: confidence interval.

The association of NLR and 90-day poor outcomes was evaluated in most of the included studies. After subgroup analysis, the pooled results of prospective studies and retrospective studies were consistent with the pooled results of five studies regarding the association of NLR and 90-day poor outcomes (Table 3 ). The pooled OR in non-China group was higher than OR in China group and there was no heterogeneity between the two studies, demonstrating that a higher NLR is associated with a higher predictive ability for 90 -day poor outcomes in nonChinese patients. In the analysis of 90-day poor outcomes (Table 3), the mean NLR of non-Chinese patients had a NLR (3.4-3.74) was higher than the NLR of Chinese patients (2.1-2.9), and the mean NLR could affect the prediction of 90-day poor outcomes in ischemic stroke. With a higher mean NLR, the predictive value for 90-day poor outcomes had a higher predictive ability with the increased pooled OR. Brooks [21] demonstrated an OR of 6.73 with a high mean NLR of 3.74, while Xue [4] report an OR for 90-day poor outcomes as 1.455 with a low NLR of 2.1. In addition, we found that the pooled OR in high mean NLR group (4.04) was higher than the OR in low mean NLR group (1.60). Although a higher NLR could predict the 90-day poor outcomes regardless of mean NLR and cut-off values, there were significant heterogeneity in low mean NLR group and low cut-off group. Thus, the NLR had a strong and reliable predictive ability for 90 day poor outcomes with high mean NLR or high cut-off values.

NLR is a time dependent variable in patients with stroke. The NLR increases with time in the first few days. Many previous studies [26-28, 34] suggested that NLR increases within $12 \mathrm{~h}$ after onset and reaches the peak levels the second day. Accurately determining the optimal time to test requires additional research. Akil [35] found that the NLR of ischemic stroke patients was significantly higher than NLR of healthy patients and suggested the NLR could predict the risk of developing ischemic stroke. In addition, one study [4] also suggested that a high NLR is associated with a higher risk of recurrent ischemic stroke. Furthermore, Buck [9] demonstrated the higher NLR was associated with larger infarct volumes in patients with AIS, rather than lymphocyte counts. Recently, the platelet to lymphocyte ratio (PLR) was considered as a novel predictor for functional outcomes in patients with stroke [36, 37]. Until now, there was one study [36] regarding the influence of PLR to ischemic stroke, with a sensitivity of $73 \%$ and specificity of $69 \%$, however, this study had the limited number of patients without multivariate regression analysis. Thus, the comparison of predictive ability between NLR and PLR needed more researches to assess.

Significant heterogeneity was presented in analysis of 90-day mortality and 90-day poor outcomes. We found that a major origin of the heterogeneity was the study by Maestrini [20]. The reason was that the OR of NLR for 90day poor outcomes was calculated by univariate regression analysis. In addition, the different treatments also could result in the heterogeneity. Maestrini [20] included patients who received IV recombinant tissue plasminogen activator, while Brooks [21] included patients who underwent endovascular stroke therapy.

\section{Limitations}

There were some limitations in this study. First, the heterogeneity was significant in the studies for 90-day mortality. Although the random-effect and the subgroup analysis were used to make the results more conservative, the association of NLR and 90-day mortality needs 
more evidence after adjusting the confounding factors. Second, treatment options varied between the studies. The therapeutic options utilized where not uniform in the same study, and in some instances they were not clearly reported. Future studies should display more treatment related information.

\section{CONCLUSIONS}

The synthesized evidence from the included studies showed that high NLR is associated with higher inhospital mortality and the 90-day poor outcomes rates in patients with ischemic stroke, especially with a high mean NLR or high cut-off value $(>5)$. Nevertheless, the optimal time of laboratory test must be studied further.

\section{ACKNOWLEDGMENTS}

The authors thank the reviewers for their constructive comments.

\section{CONFLICTS OF INTEREST}

No conflicts of interest.

\section{FUNDING}

This work is supported by Science and technology supportive project of Sichuan Province. Project: Intracerebral haemorrhage prevention and diagnostic treatment skills (No. 2015SZ0051); Outstanding subject development 135 project: An international, multicenter, large sample randomized controlled trial of supratentorial deep intracerebral haematoma surgery and conservative treatment in adults (No. ZY2016102); and the projects of National Natural Science Foundation of China (contract/ grant number: 81100925,81472361$)$.

\section{REFERENCES}

1. van Asch CJ, Luitse MJ, Rinkel GJ, van der Tweel I, Algra A, Klijn CJ. Incidence, case fatality, and functional outcome of intracerebral haemorrhage over time, according to age, sex, and ethnic origin: a systematic review and meta-analysis. Lancet Neurol. 2010; 9:167-76. https://doi. org/10.1016/S1474-4422(09)70340-0.

2. Steiner T, Al-Shahi Salman R, Beer R, Christensen H, Cordonnier C, Csiba L, Forsting M, Harnof S, Klijn CJ, Krieger D, Mendelow AD, Molina C, Montaner J, et al. European stroke organisation (ESO) guidelines for the management of spontaneous intracerebral hemorrhage. Int J Stroke. 2014; 9:840-55. https://doi.org/10.1111/ijs.12309.

3. Allen CL, Bayraktutan U. Oxidative stress and its role in the pathogenesis of ischaemic stroke. Int J Stroke. 2009; 4:46170. https://doi.org/10.1111/j.1747-4949.2009.00387.x.
4. Xue J, Huang W, Chen X, Li Q, Cai Z, Yu T, Shao B. Neutrophil-to-lymphocyte ratio is a prognostic marker in acute ischemic stroke. J Stroke Cerebrovasc Dis. 2017; 26:650-7. https://doi.org/10.1016/j.jstrokecerebrovas dis.2016.11.010.

5. Herminawati L, Wijaya A, Arief M, As'ad S. The association of plasma fractalkine and inflammation after ischemic stroke. Indonesian Biomedical Journal. 2016; 8:109-14. https://doi.org/10.18585/inabj.v8i2.205.

6. Worthmann H, Tryc AB, Deb M, Goldbecker A, Ma YT, Tountopoulou A, Lichtinghagen R, Weissenborn K. Linking infection and inflammation in acute ischemic stroke. Ann N Y Acad Sci. 2010; 1207:116-22. https://doi. org/10.1111/j.1749-6632.2010.05738.x.

7. VanGilder RL, Davidov DM, Stinehart KR, Huber JD, Turner RC, Wilson KS, Haney E, Davis SM, Chantler PD, Theeke L, Rosen CL, Crocco TJ, Gutmann L, et al. $\mathrm{C}$-reactive protein and long-term ischemic stroke prognosis. J Clin Neurosci. 2014; 21:547-53. https://doi.org/10.1016/j. jocn.2013.06.015.

8. Furlan JC, Vergouwen MDI, Fang J, Silver FL. White blood cell count is an independent predictor of outcomes after acute ischaemic stroke. Eur J Neurol. 2014; 21:215-22. https://doi.org/10.1111/ene.12233.

9. Buck BH, Liebeskind DS, Saver JL, Bang OY, Yun SW, Starkman S, Ali LK, Kim D, Villablanca JP, Salamon N, Razinia T, Ovbiagele B. Early neutrophilia is associated with volume of ischemic tissue in acute stroke. Stroke. 2008; 39:355-60. https://doi.org/10.1161/Strokeaha.107.490128.

10. Yin Y, Wang J, Wang X, Gu L, Pei H, Kuai S, Zhang Y, Shang Z. Prognostic value of the neutrophil to lymphocyte ratio in lung cancer: a meta-analysis. Clinics (Sao Paulo). 2015; 70:524-30. https://doi.org/10.6061/clinics/2015(07)10.

11. Dowlatshahi D, Wasserman JK, Momoli F, Petrcich W, Stotts G, Hogan M, Sharma M, Aviv RI, Demchuk AM, Chakraborty S. Evolution of computed tomography angiography spot sign is consistent with a site of active hemorrhage in acute intracerebral hemorrhage. Stroke. 2014; 45:277-80. https://doi.org/10.1161/strokeaha.113.003387.

12. Arbel Y, Finkelstein A, Halkin A, Birati EY, Revivo M, Zuzut M, Shevach A, Berliner S, Herz I, Keren G, Banai S. Neutrophil/lymphocyte ratio is related to the severity of coronary artery disease and clinical outcome in patients undergoing angiography. Atherosclerosis. 2012; 225:45660. https://doi.org/10.1016/j.atherosclerosis.2012.09.009.

13. Tamhane UU, Aneja S, Montgomery D, Rogers EK, Eagle KA, Gurm HS. Association between admission neutrophil to lymphocyte ratio and outcomes in patients with acute coronary syndrome. Am J Cardiol. 2008; 102:653-7. https:// doi.org/10.1016/j.amjcard.2008.05.006.

14. Tao C, Hu X, Wang J, Ma J, Li H, You C. Admission neutrophil count and neutrophil to lymphocyte ratio predict 90-day outcome in intracerebral hemorrhage. Biomark Med. 2017; 11:33-42. https://doi.org/10.2217/ bmm-2016-0187. 
15. Lattanzi S, Cagnetti C, Provinciali L, Silvestrini M. Neutrophilto-lymphocyte ratio and neurological deterioration following acute cerebral hemorrhage. Oncotarget. 2017; 8:57489-94. https://doi.org/10.18632/oncotarget.15423.

16. Lattanzi S, Cagnetti C, Provinciali L, Silvestrini M. Neutrophil-to-lymphocyte ratio predicts the outcome of acute intracerebral hemorrhage. Stroke. 2016; 47:1654-7. https://doi.org/10.1161/strokeaha.116.013627.

17. Fang YN, Tong MS, Sung PH, Chen YL, Chen CH, Tsai NW, Huang CJ, Chang YT, Chen SF, Chang WN, Lu CH, Yip HK. Higher neutrophil counts and neutrophil-to-lymphocyte ratio predict prognostic outcomes in patients after non-atrial fibrillation-caused ischemic stroke. Biomed J. 2017; 40:154 62. https://doi.org/10.1016/j.bj.2017.03.002.

18. Fan L, Gui L, Chai EQ, Wei CJ. Routine hematological parameters are associated with short- and long-term prognosis of patients with ischemic stroke. J Clin Lab Anal. 2017. https://doi.org/10.1002/jcla.22244.

19. Celikbilek A, Ismailogullari S, Zararsiz G. Neutrophil to lymphocyte ratio predicts poor prognosis in ischemic cerebrovascular disease. J Clin Lab Anal. 2014; 28:27-31. https://doi.org/10.1002/jcla.21639.

20. Maestrini I, Strbian D, Gautier S, Haapaniemi E, Moulin S, Sairanen T, Dequatre-Ponchelle N, Sibolt G, Cordonnier C, Melkas S, Leys D, Tatlisumak T, Bordet R. Higher neutrophil counts before thrombolysis for cerebral ischemia predict worse outcomes. Neurology. 2015; 85:1408-16. https://doi.org/10.1212/WNL.037741R2037741R22029.

21. Brooks SD, Spears C, Cummings C, VanGilder RL, Stinehart KR, Gutmann L, Domico J, Culp S, Carpenter J, Rai A, Barr TL. Admission neutrophil-lymphocyte ratio predicts 90 day outcome after endovascular stroke therapy. J Neurointerv Surg. 2014; 6:578-83. https://doi.org/10.1136/ neurintsurg-2013-010780.

22. Qun S, Tang Y, Sun J, Liu Z, Wu J, Zhang J, Guo J, Xu Z, Zhang D, Chen Z, Hu F, Xu X, Ge W. Neutrophil-tolymphocyte ratio predicts 3-month outcome of acute ischemic stroke. Neurotox Res. 2017; 31:444-52. https:// doi.org/10.1007/s12640-017-9707-z.

23. Zhai MM, Wang JP, Yu L, Fu XJ, Li LY. Neutrophil and lymphocyte ratios for the predictive analysis of the prognosis in patients with acute cerebral infarction. Chin J Cerebrovasc Dis. 2017; 14:5.

24. Stovold E, Beecher D, Foxlee R, Noel-Storr A. Study flow diagrams in cochrane systematic review updates: an adapted PRISMA flow diagram. Syst Rev. 2014; 3:54. https://doi. org/10.1186/2046-4053-3-54.

25. Stang A. Critical evaluation of the newcastle-ottawa scale for the assessment of the quality of nonrandomized studies in meta-analyses. Eur J Epidemiol. 2010; 25:603-5. https:// doi.org/10.1007/s10654-010-9491-z.

26. Gong C, Hoff JT, Keep RF. Acute inflammatory reaction following experimental intracerebral hemorrhage in rat. Brain Res. 2000; 871:57-65.
27. Xue MZ, Del Bigio MR. Intracortical hemorrhage injury in rats - relationship between blood fractions and brain cell death. Stroke. 2000; 31:1721-7.

28. Xue M, Del Bigio MR. Comparison of brain cell death and inflammatory reaction in three models of intracerebral hemorrhage in adult rats. J Stroke Cerebrovasc Dis. 2003; 12:152-9. https://doi.org/10.1016/S1052-3057(03)00036-3.

29. Sun Y, You S, Zhong C, Huang Z, Hu L, Zhang X, Shi J, Cao Y, Liu CF. Neutrophil to lymphocyte ratio and the hematoma volume and stroke severity in acute intracerebral hemorrhage patients. Am J Emerg Med. 2017; 35:429-33. https://doi.org/10.1016/j.ajem.2016.11.037.

30. Tokgoz S, Kayrak M, Akpinar Z, Seyithanoglu A, Guney F, Yuruten B. Neutrophil lymphocyte ratio as a predictor of stroke. J Stroke Cerebrovasc Dis. 2013; 22:1169-74. https:// doi.org/10.1016/j.jstrokecerebrovasdis.2013.01.011.

31. Fiorelli M, Bastianello S, von Kummer R, del Zoppo GJ, Larrue V, Lesaffre E, Ringleb AP, Lorenzano S, Manelfe C, Bozzao L. Hemorrhagic transformation within 36 hours of a cerebral infarct: relationships with early clinical deterioration and 3-month outcome in the european cooperative acute stroke study I (ECASS I) cohort. Stroke. 1999; 30:2280-4.

32. Posada-Duque RA, Barreto GE, Cardona-Gomez GP. Protection after stroke: cellular effectors of neurovascular unit integrity. Front Cell Neurosci. 2014; 8:231. https://doi. org/10.3389/fncel.2014.00231.

33. Tokgoz S, Keskin S, Kayrak M, Seyithanoglu A, Ogmegul A. Is neutrophil/lymphocyte ratio predict to short-term mortality in acute cerebral infarct independently from infarct volume? J Stroke Cerebrovasc Dis. 2014; 23:2163-8. https://doi.org/10.1016/j.jstrokecerebrovasdis.2014.04.007.

34. Giede-Jeppe A, Bobinger T, Gerner ST, Sembill JA, Sprugel MI, Beuscher VD, Lucking H, Hoelter P, Kuramatsu JB, Huttner HB. Neutrophil-to-lymphocyte ratio is an independent predictor for in-hospital mortality in spontaneous intracerebral hemorrhage. Cerebrovasc Dis. 2017; 44:26-34. https://doi.org/10.1159/000468996.

35. Akil E, Akil MA, Varol S, Ozdemir HH, Yucel Y, Arslan D, Akyuz A, Alan S. Echocardiographic epicardial fat thickness and neutrophil to lymphocyte ratio are novel inflammatory predictors of cerebral ischemic stroke. J Stroke Cerebrovasc Dis. 2014; 23:2328-34. https://doi. org/10.1016/j.jstrokecerebrovasdis.2014.04.028.

36. Altintas O, Altintas MO, Tasal A, Kucukdagli OT, Asil T. The relationship of platelet-to-lymphocyte ratio with clinical outcome and final infarct core in acute ischemic stroke patients who have undergone endovascular therapy. Neurol Res. 2016; 38:759-65. https://doi.org/10.1080/0161 6412.2016.1215030.

37. Tao C, Wang J, Hu X, Ma J, Li H, You C. Clinical value of neutrophil to lymphocyte and platelet to lymphocyte ratio after aneurysmal subarachnoid hemorrhage. Neurocrit Care. 2017; 26:393-401. https://doi.org/10.1007/ s12028-016-0332-0. 